\title{
Clinical Audit on Quality of postoperative Nursing Care provided to women undergoing Cesarean Section at Woman's Health Hospital, Assuit University
}

\author{
Magda Ahmed Farahat ${ }^{1}$, Mahmoud Ahmed Mahmoud ${ }^{2}$ \& Ghadah Abdelrahman Mahmoud $^{3}$ \\ ${ }^{1}$ Clinical Demonstrator of Obstetrics \& Gynecological Nursing, Faculty of Nursing, Assiut University, Egypt. \\ ${ }^{2}$ Professor of Obstetrics \& Gynecology, Faculty of Medicine, Assiut University, Egypt. \\ ${ }^{3}$ Assistant Professor of Obstetrics \& Gynecological Nursing, Faculty of Nursing, Assiut University, Egypt.
}

\begin{abstract}
Background: Clinical audit is "a quality improvement process that seeks to improve patient care and outcomes through systematic review of care against explicit criteria and the implementation of change". Objectives: (1) Audit on the current postoperative nursing care provided to women who had Cesarean Section at woman's health hospital, Assuit. (2)Assess the hospital based rate of Cesarean Section patients and method: A criterion based audit research design was conducted at postpartum ward from February 2016 to July 2016, A total of 618 post cesarean women in preorientation period and 50 women in post orientation period were recruited. Interview questionnaire schedule for mothers and nurses(11) was carried out and observational checklist was used to collect the data. Results: there was significant improvement related to monitoring vital signs, palpating fundus and surgical site care.Conclusion: There was a big gap between the current and the ideal practices of care. The total number of all deliveries was 13115 . The number of cesarean sections only was 6064 (46.2\%). Recommendations: Increasing number of nursing staff, Nurses in post natal unit should have training courses, qualified staff should be recruited, further research studies are needed.
\end{abstract}

\section{Keywords: Clinical Audit, Quality \& Cesarean Section.}

\section{Introduction}

Cesarean birth is to have a baby through cutting done on the mother's abdomen and uterus (ACOG, 2015). World health report in year 2010 revealed that , there were almost 18.5 million CS performed every year around the world (Gibbons, 2010) In 2011, about one third of women in USA delivered by cesarean section (Gregory, et al., 2012). The Egyptian Demographic Health Survey in year 2014 received data on the frequency of caesarean sections showed that more than half of deliveries in the five-year period before the survey were by cesarean section. The liability of cesarean delivery is increased by increasing the age of women and decreased with the birth order of children. Also it stated that percentage of women who delivered by cesarean section before the survey by 5 years in Assuit was 34.8\%. The total Cesarean Section rate in Egypt is $51.8 \%$ (EDHS, 2014).

"Clinical audit is the process of a quality improvement which aims to improve the quality of care provided to patients and their outcomes through regular and systematic revision of the care according to basic and standardized criteria and the application of needed change". Reviewing of care included three domains "structure, process and outcomes" which selected and evaluated in a systematic way according to explicit criteria. Where needed changes are implemented at all levels (individual, team, or service) and further following up is used to make sure that health care delivery is improved (Clinical Audit Support Centre, 2015)

Providing Low-qualified obstetric care in low- and middle-income countries leads to increase maternal mortality rate in hospitals. Criterion-based clinical audits are increasingly used to measure and improve obstetric care in these settings (Pirkle, 2011) Quality health care is to do the right thing at the right time in the right way to achieve the best possible results. (TriStar Horizon Medical Center, 2010) The comptence to give good-quality facility-based care to women after cesarean section is one important component of providing services which save lives for women and neonates. Direct observation of cesarean section deliveries give us the chance to assess a number of procedures which done after operation that are often not described in medical records in low income countaries (Evans et al., 2014)

\section{Significance of the study}

Low-quality obstetric care in low- and middleincome countries contributes to high in-hospital maternal mortality Criterion-based clinical audits are increasingly used to measure and improve obstetric care in these settings (Pirkle, et al., 2011).

Objectives of the study

The primary objective of the study was to: Audit on the current postoperative nursing care provided to women who had Cesarean Section and identify the gap between the current and ideal practices at Women's Health Hospital, Assiut University. 
The secondary objective of the study was to Assess the hospital based rate of Cesarean Section among women at the same hospital.

Patients and methods

Technical design

Research design

The current study used A criterion based audit research design.

\section{Setting of the study}

This study was conducted at postpartum ward at Woman's Health Hospital, Asyut city.

\section{Patients:}

The study included 668 women who underwent by cesarean section at woman's health hospital, Assiut University in who divided as 618 women in preorientation period and 50 women in post orientation period during the study period from February 2016 to july (2016) when they met the inclusion criteria.

\section{Inclusion criteria}

- Women who accepted to participate.

- Women who delivered by cesarean section.

Tools of the study

Three tools were used in this study classified to: $1^{\text {st }}$ tool ( structured interview questionnaire schedule for mothers), $2^{\text {nd }}$ tool (structured interview questionnaire schedule for nurses) and $3^{\text {rd }}$ tool (an observational checklist for nurses which designed and developed by Royal College Of Obstetricians and Gynecologists (RCOG) 2011(NICE guidelines) and guidelines of Vanderbilt University Medical Centre 2013).

\section{These tools were classified as following}

\section{Tool 1}

A structured Interview Questionnaire for women which was divided as following:-

Part (1): personal data of mothers (name, age, residence, educational level, occupation).

Part (2): Obstetric history (parity, abortions , stillbirths, neonatal deaths, number of living children, Modes of previous deliveries and Previous indications of last cesarean section)

Part (3): Current antenatal condition (Gestational age, Current antenatal risk factors)

Part (4): Data related to current cesarean section delivery

Date of operation ,Cesarean section order ,Indications of current cesarean section, Attendant at Cesarean Section, Type of cesarean section(elective or emergency), Type of anesthesia ,Neonatal birth weight, Intraoperative complications, Date of discharge and Post-operative complications

Tool (2): Personal data of nurses: age, years of experience, level of education, attending related training program

Tool (3): Clinical Audit Chart (observational checklist) which designed and developed by Royal
College Of Obstetricians and Gynecologists (RCOG) 2011(NICE guidelines) and guidelines of Vanderbilt University Medical Centre (2013) based on standards of essential obstetric nursing care for cesarean section women by mixing the two guidelines and modified by the investigator by adding three columns in front of each item of care (done, not done and barriers for items which not done) It reviewed by expertises from the medical and nursing staff of obstetrics and gynecology, It includes the following items

Maternal vital signs: Monitor(T,P,R and $B P$ ), Giving fluid to hypotensive women and monitoring oxygen saturation)

Maternal comfort and assessment: (Complete head to toe physical assessment and Assist the woman to position herself comfortably and assist in breast feeding)

Assessment for Perineum and fundus :( giving oxytocin, palpating fundus and assessing lochia)

Assessment for Surgical site: (removing the dressing 24 hour after CS and specific monitoring for fever and Assessing the wound for infection, bleeding)

Fluid Input such as: (Assess IV site, Measure and record all intake)

Bladder management such as :( assessing bladder distension, verify Foley catheter and Remove indwelling catheter 36 hrs. after birth)

Mobilization such as: (Encourage early mobilization, sitting the woman out of bed as soon as maternal condition allows, Advice the woman not to ambulate from bed in the first time without the help of nurse).

Care of baby born by CS such as: (A practitioner skilled in the resuscitation of the newborn should be present, Maintain thermal care of the newborn and Encourage early skin to skin contact)

Pain management such as :( All pain medications ordered by anesthesia team and Assess patient comfort on admission to recovery area)

Transport and discharge from recovery area. Nursing implications such as: (Notifying staff about any abnormalities in pt vital signs, sensation, fluid intake and pain sensation).

Discharge planning such as: (Routine postnatal care , impact of CS for future pregnancies , Resumption of normal activities)

Timing of discharge (length of hospital stay)

- The barriers that prevent nurses from providing care according to these guidelines were assessed.

Operational design

Preparatory phase

The researcher reviewed related literature (local \& international) using textbooks, web articles and scientific magazines then the tools were prepared. 


\section{Validity}

The tools were reviewed for validity by 3 experts in obstetrics and gynecology (medical \& nursing).

\section{Pilot study}

It performed to investigate the content validity of study tools. It was carried out on $10 \%$ of subjects

(62) in the first phase those subjects were excluded from the study.

\section{Field work}

The study was carried out during the period from February 2016 to july (2016).

\section{Administrative design}

The study was approved from ethical committee of the Faculty of Nursing; Assiut University and obtaining an official permission from the manager of Woman's Health Hospital to proceed with the study.

\section{Ethical considerations}

Oral consent was obtained from women who were participated in the study, after explaining the nature and purpose of the study. There was no any risk for the women during conduction of the study. The study was followed common ethical principles in clinical research. Confidentiality and anonymity was assured and the participating women had the right to refuse participation or withdraw from the study without any rational.

\section{The procedure}

I-The first phase ( pre orientation phase)(It take 6 months): was carried out to audit on the current nursing care provided to women after cesarean section to identify the gap between the current and ideal practices of post cesarean section nursing care and identify the barriers that prevented nurses from giving the ideal care by using an observational checklist derived from the national guidelines of royal college (NICE guidelines 2011) and Vanderbilt University Medical Centre guidelines to assess nurses in postpartum ward while they were providing care to cesarean section women and comparing this actual care with these guidelines so An official permission was obtained from the manager of Woman's Health Hospital , Assiut University to proceed with this study, oral consent from women who participated in this study was obtained, all post cesarean section women were interviewed by the investigator by face to face communication to collect data related to maternal interviewing questionnaire. Each interview was taken about 10-15 minutes. As regards clinical audit chart (the observational checklist).the investigator observed the post cesarean section nursing care provided to women (618) who had cesarean section as the investigator recorded which care was done and which care was not done and what were the barriers (causes) that made nurses not to do these items of care .Data collected through six months that started on February 2016 to july (2016). At the end of the audit phase, the investigator tabulated the data to stand on the gap between the current and ideal practices by asking nurses about the cause of not doing the ideal care

II-Second phase (post orientation phase)(It take 1 month):this phase conducted as following (preparatory stage and implementation stage)on the light of results of the first phase and the gaps identified an educational booklet for nurses was done based on the NICE guidelines and guidelines of Vanderbuilt university translated into Arabic to educate the nurses about the ideal post cesarean section nursing care.

1-the preparatory phase: to facilitate the implementation of the educational booklet the investigator prepared the tool(interview for nurses and clinical audit chart of educational booklet, training place) following by arranging of sessions which scheduled based on the contents of the educational booklet ,number of staff involved, time availability and shifts of nurses.

\section{Implementation phase}

Before explaining the educational booklet the purpose of the study was explained to the nurses in post partum ward. The investigator scheduled with the nurses the teaching sessions and the nurses were divided into small groups. Each group had 2 nurses and sometimes internship students of faculty of nurses were present. According to their workload, each group of nurses was given the freedom to choose their optimal time for receiving the teaching session whenever they had minimal workload. The educational booklet discussed with the nurses in three sessions each session take one hour because there was some interruptions as some women need something or anew women came from operating room .Feedback and reinforcement of teaching was performed according to the nurses needs to ensure their understanding and a copy of this booklet was given to each nurse in addition to this two copies were given to the head nurse of women health hospital to refresh the knowledge of postpartum ward nurses every period and to give the knowledge to the new recruited nurses

After this phase the investigator let nurses three weeks then went again to them to observe them while they were giving the post cesarean section nursing care to (50) women only during one week in each shift (morning, evening and night shift) to observe all nurses while they were giving care as the investigator marked on the observational checklist which care was done and which care was not done ,the investigator noted that some items of care were improved as there were some internship students of faculty of nursing who did some care like measuring vital signs, doing 
uterine massage, assisting women in ambulating and in breast feeding as the official nurses didn't have time to do this at the end of this phase the investigator tabulated the data.

-The researcher provided the women with health education about post cesarean section home care.

-The researcher assessed the hospital based rate of cesarean section by monthly calculating the number of cesarean sections for one year.

\section{Statistical analysis}

Date entry and data analysis were done using SPSS version 19 (Statistical Package for Social Science).
Data were presented as number and percentage. Chisquare test was used to compare between qualitative variables. P-value considered statistically significant when $\mathrm{P}<0.05$.

Limitations of the study

Few number of post orientation sessions were done because of lack of time. Few numbers of cases were studied in post orientation period. There was a difficulty to applicate the ideal care from nurses because of lack of resources, lack of nursing personnel and work overload.

\section{Results}

Table (1): Distribution of studied women according to personal data.

\begin{tabular}{|c|c|c|c|c|c|}
\hline & \multicolumn{2}{|c|}{$\begin{array}{c}\text { Pre-orientation } \\
(n=618)\end{array}$} & \multicolumn{2}{|c|}{$\begin{array}{c}\text { Post-orientation } \\
(n=50)\end{array}$} & \multirow[t]{2}{*}{ P-value } \\
\hline & No. & $\%$ & No. & $\%$ & \\
\hline \multicolumn{5}{|l|}{ Age } & \multirow{4}{*}{0.187} \\
\hline$<19$ & 30 & 4.9 & 0 & 0.0 & \\
\hline $19-30$ & 412 & 66.7 & 38 & 76.0 & \\
\hline$>30$ & 176 & 28.5 & 12 & 24.0 & \\
\hline \multicolumn{6}{|l|}{ Education } \\
\hline Illiterate & 242 & 39.2 & 15 & 30.0 & 0.200 \\
\hline Read \&write & 13 & 2.1 & 2 & 4.0 & 0.311 \\
\hline Primary school & 74 & 12.0 & 6 & 12.0 & 0.996 \\
\hline Preparatory school & 68 & 11.0 & 6 & 12.0 & 0.829 \\
\hline Secondary school & 166 & 26.9 & 15 & 30.0 & 0.631 \\
\hline University & 52 & 8.4 & 6 & 12.0 & 0.428 \\
\hline Post university & 3 & 0.5 & 0 & 0.0 & 0.621 \\
\hline \multicolumn{5}{|l|}{ Residence } & \multirow{3}{*}{0.504} \\
\hline Rural & 522 & 84.5 & 44 & 88.0 & \\
\hline Urban & 96 & 15.5 & 6 & 12.0 & \\
\hline \multicolumn{5}{|l|}{ Occupation } & \multirow{3}{*}{0.881} \\
\hline Housewife & 552 & 89.3 & 45 & 90.0 & \\
\hline Employer & 66 & 10.7 & 5 & 10.0 & \\
\hline
\end{tabular}

Table (2): Distribution of studied women according to audit of post cesarean CS nursing care (vital signs, Maternal comfort, Perineum \&Fundus, Surgical site).

\begin{tabular}{|c|c|c|c|c|c|c|c|c|c|}
\hline & \multicolumn{4}{|c|}{$\begin{array}{c}\text { Pre-orientation } \\
(\mathrm{n}=618)\end{array}$} & \multicolumn{4}{|c|}{$\begin{array}{c}\text { Post-orientation } \\
(\mathrm{n}=\mathbf{5 0})\end{array}$} & \multirow{3}{*}{ P-value } \\
\hline & \multicolumn{2}{|c|}{ Yes } & \multicolumn{2}{|c|}{ No } & \multicolumn{2}{|c|}{ Yes } & \multicolumn{2}{|c|}{ No } & \\
\hline & No. & $\%$ & No. & $\%$ & No. & $\%$ & No. & $\%$ & \\
\hline \multicolumn{10}{|l|}{ Monitoring of vital signs } \\
\hline $\begin{array}{l}\text { Monitoring BP, } \mathrm{P}, \mathrm{Res} / 15 \mathrm{~min} \text { then } / 30 \\
\text { min then /hour until discharge from } \\
\text { recovery }\end{array}$ & 124 & 20.1 & 494 & 79.9 & 24 & 48.0 & 26 & 52.0 & $0.000 *$ \\
\hline $\begin{array}{l}\text { Monitoring temperature upon arrival,if } \\
\text { not normal repeat } / 15 \text { min until become } \\
\text { normal }\end{array}$ & 223 & 36.1 & 395 & 63.9 & 31 & 62.0 & 19 & 38.0 & $0.000 *$ \\
\hline $\begin{array}{l}\text { Giving fluids and oxygen if pt } \\
\text { hypotensive }\end{array}$ & 587 & 95 & 31 & 5.0 & 50 & 100.0 & 0 & 0.0 & 0.105 \\
\hline
\end{tabular}




\begin{tabular}{|c|c|c|c|c|c|c|c|c|c|}
\hline & \multicolumn{4}{|c|}{$\begin{array}{c}\text { Pre-orientation } \\
(\mathrm{n}=618)\end{array}$} & \multicolumn{4}{|c|}{$\begin{array}{c}\text { Post-orientation } \\
(\mathbf{n}=50)\end{array}$} & \multirow{3}{*}{ P-value } \\
\hline & \multicolumn{2}{|c|}{ Yes } & \multicolumn{2}{|c|}{ No } & \multicolumn{2}{|c|}{ Yes } & \multicolumn{2}{|c|}{ No } & \\
\hline & No. & $\%$ & No. & $\%$ & No. & $\%$ & No. & $\%$ & \\
\hline Monitor $\mathrm{SaO} 2$ via pulse oximeter & 0 & 0.0 & 618 & 100.0 & 0 & 0.0 & 50 & 100.0 & -- \\
\hline \multicolumn{10}{|l|}{ Maternal comfort \& assessment } \\
\hline $\begin{array}{l}\text { Complete head to toe physical } \\
\text { assessment }\end{array}$ & 0 & 0.0 & 618 & 100.0 & 0 & 0.0 & 50 & 100.0 & -- \\
\hline Assist woman in positioning \&feeding & 37 & 6.0 & 581 & 94.0 & 14 & 28.0 & 36 & 72.0 & $0.000 *$ \\
\hline \multicolumn{10}{|l|}{ Perineum \&Fundus } \\
\hline $\begin{array}{l}\text { Administer 15-unit oxytocin in } 250 \mathrm{ml} \\
\text { NS }\end{array}$ & 123 & 19.9 & 495 & 80.1 & 12 & 24.0 & 38 & 76.0 & 0.488 \\
\hline $\begin{array}{l}\text { Palpate uterine fundus } / 15 \text { min for } 1 \\
\text { hour then } / 30 \text { min for } 1 \text { hour then/ hour } \\
\text { until discharge from recovery }\end{array}$ & 148 & 23.9 & 470 & 76.1 & 32 & 64.0 & 18 & 36.0 & $0.000 *$ \\
\hline $\begin{array}{l}\text { Assess amount and character of lochia, } \\
\text { noting clots }\end{array}$ & 618 & 100.0 & 0 & 0.0 & 50 & 100.0 & 0 & 0.0 & -- \\
\hline \multicolumn{10}{|l|}{$\overline{\text { Surgical site }}$} \\
\hline Remove the dressing 24 hour after CS & 13 & 2.1 & 605 & 97.9 & 4 & 8.0 & 46 & 92.0 & $0.032 *$ \\
\hline Specific Monitoring for fever & 173 & 28.0 & 445 & 72.0 & 50 & 100.0 & 0 & 0.0 & $0.000 *$ \\
\hline $\begin{array}{l}\text { Assessing wound for infection, bleeding } \\
\text { and separation }\end{array}$ & 370 & 59.9 & 248 & 40.1 & 43 & 86.0 & 7 & 14.0 & $0.000 *$ \\
\hline $\begin{array}{l}\text { Encourage woman to wear loose } \\
\text { comfortable clothes }\end{array}$ & 25 & 4.0 & 593 & 96.0 & 8 & 16.0 & 42 & 84.0 & $0.002 *$ \\
\hline Gently cleaning \& drying wound daily & 87 & 14.1 & 531 & 85.9 & 13 & 26.0 & 37 & 74.0 & $0.023^{*}$ \\
\hline
\end{tabular}

Table (3): Distribution of studied women according to audit of post cesarean section nursing care (Fluid input, Bladder management, Mobilization, Care of baby).

\begin{tabular}{|c|c|c|c|c|c|c|c|c|c|}
\hline & \multicolumn{4}{|c|}{ Pre-orientation } & \multicolumn{4}{|c|}{ Post-orientation } & \multirow{3}{*}{ P-value } \\
\hline & \multicolumn{2}{|c|}{ Yes } & \multicolumn{2}{|c|}{ No } & \multicolumn{2}{|c|}{ Yes } & \multicolumn{2}{|c|}{ No } & \\
\hline & No. & $\%$ & No. & $\%$ & No. & $\%$ & No. & $\%$ & \\
\hline \multicolumn{10}{|l|}{ Fluid input } \\
\hline $\begin{array}{l}\text { Assess iv site for appearance } \& \text { patency } \\
\text { initially and } / 2 \text { hours }\end{array}$ & 0 & 0.0 & 618 & 100.0 & 9 & 18.0 & 41 & 82.0 & $0.000^{*}$ \\
\hline $\begin{array}{l}\text { Measure and record all intake every } 2 \mathrm{hr} \\
\text { until iv discontinued }\end{array}$ & 0 & 0.0 & 618 & 100.0 & 0 & 0.0 & 50 & 100.0 & -- \\
\hline \multicolumn{10}{|l|}{ Bladder management } \\
\hline $\begin{array}{l}\text { Assess bladder distension upon } \\
\text { admission \& with each fundal assess }\end{array}$ & 88 & 14.2 & 530 & 85.8 & 10 & 20.0 & 40 & 80.0 & 0.268 \\
\hline $\begin{array}{l}\text { Verify foley catheter is patent and note } \\
\text { volume of urine }\end{array}$ & 531 & 85.9 & 87 & 14.1 & 48 & 96.0 & 2 & 4.0 & $0.044^{*}$ \\
\hline Remove catheter $36 \mathrm{hrs}$ after birth & 0 & 0.0 & 618 & 100.0 & 3 & 6.0 & 47 & 94.0 & $0.000^{*}$ \\
\hline $\begin{array}{l}\text { Measure urine output after removal of } \\
\text { catheter }\end{array}$ & 0 & 0.0 & 618 & 100.0 & 0 & 0.0 & 50 & 100.0 & -- \\
\hline $\begin{array}{l}\text { Notify medical staff if there are } \\
\text { bladder function problems }\end{array}$ & 580 & 93.9 & 38 & 6.1 & 50 & 100.0 & 0 & 0.0 & 0.104 \\
\hline \multicolumn{10}{|l|}{ Mobilization } \\
\hline Encourage early mobilization & 580 & 93.9 & 38 & 6.1 & 50 & 100.0 & 0 & 0.0 & 0.104 \\
\hline $\begin{array}{l}\text { Sitting the woman out of bed as } \\
\text { soon as condition allows }\end{array}$ & 13 & 2.1 & 605 & 97.9 & 5 & 10.0 & 45 & 90.0 & $0.008^{*}$ \\
\hline $\begin{array}{l}\text { Nurse present when woman first } \\
\text { ambulate }\end{array}$ & 0 & 0.0 & 618 & 100.0 & 5 & 10.0 & 45 & 90.0 & $0.000 *$ \\
\hline $\begin{array}{l}\text { Check woman pressure areas when } \\
\text { return to ward }\end{array}$ & 0 & 0.0 & 618 & 100.0 & 0 & 0.0 & 50 & 100.0 & -- \\
\hline
\end{tabular}




\begin{tabular}{|c|c|c|c|c|c|c|c|c|c|}
\hline & \multicolumn{4}{|c|}{ Pre-orientation } & \multicolumn{4}{|c|}{ Post-orientation } & \multirow{3}{*}{ P-value } \\
\hline & \multicolumn{2}{|c|}{ Yes } & \multicolumn{2}{|c|}{ No } & \multicolumn{2}{|c|}{ Yes } & \multicolumn{2}{|c|}{ No } & \\
\hline & No. & $\%$ & No. & $\%$ & No. & $\%$ & No. & $\%$ & \\
\hline \multicolumn{10}{|l|}{ Care of baby } \\
\hline $\begin{array}{l}\text { Practitioner skilled in newborn } \\
\text { resuscitation present }\end{array}$ & 618 & 100.0 & 0 & 0.0 & 50 & 100.0 & 0 & 0.0 & -- \\
\hline Maintain thermal care of newborn & 618 & 100.0 & 0 & 0.0 & 50 & 100.0 & 0 & 0.0 & -- \\
\hline $\begin{array}{l}\text { Encourage skin to skin contact } \\
\text { between woman \& newborn }\end{array}$ & 0 & 0.0 & 618 & 100.0 & 0 & 0.0 & 50 & 100.0 & -- \\
\hline $\begin{array}{l}\text { Offer support to help woman start } \\
\text { breast feeding }\end{array}$ & 13 & 2.1 & 605 & 97.9 & 4 & 8.0 & 46 & 92.0 & $0.032 *$ \\
\hline
\end{tabular}

Table (4): Hospital based rate of cesarean section year 2016.

\begin{tabular}{|l|c|c|c|c|c|}
\hline \multirow{2}{*}{} & \multicolumn{2}{|c|}{ C.S. } & \multicolumn{2}{c|}{ Vaginal } & \multirow{2}{*}{ Total } \\
\cline { 2 - 5 } January & No. & \% & No. & \% & 1140 \\
\hline February & 559 & 49.0 & 581 & 51.0 & 1051 \\
\hline March & 483 & 46.0 & 568 & 54.0 & 994 \\
\hline April & 477 & 48.0 & 517 & 52.0 & 1031 \\
\hline May & 470 & 45.6 & 561 & 54.4 & 957 \\
\hline June & 447 & 46.7 & 510 & 53.3 & 1071 \\
\hline July & 453 & 42.3 & 618 & 57.7 & 1274 \\
\hline August & 592 & 46.5 & 682 & 53.5 & 1227 \\
\hline September & 540 & 44.0 & 687 & 56.0 & 963 \\
\hline October & 360 & 37.4 & 603 & 62.6 & 1133 \\
\hline November & 542 & 47.8 & 591 & 52.2 & 1188 \\
\hline December & 599 & 50.4 & 589 & 49.6 & 1086 \\
\hline Total & 542 & 49.9 & 544 & 50.1 & 13115 \\
\hline
\end{tabular}

Table (1): Shows that more than two thirds of the studied women in age between 19-30 and more than one third of them were illiterate and the great majority of them were housewives from rural areas with no statistically significant difference in pre and post orientation period.

Table (2): Shows that there was significant improvement related to most items like monitoring vital signs except in measuring oxygen saturation, also there were significant improvement in assisting woman in positioning\& feeding, palpating fundus and in all items of surgical site care.

Table (3): Shows that there were significant improvement in assessing IV site, verifying foley catheter ,sitting woman out of bed, nurse present when woman first ambulate, offer support in breast feeding.

Table (4): Shows that the total number of all deliveries (normal vaginal deliveries \&cesarean sections) was 13115.the number of cesarean sections only was 6064(46.2\%) and normal deliveries was $7051(53.8 \%)$.

\section{Discussion}

Audit measures current practice against a defined (desired) standard. It forms part of clinical governance, Which aims to safeguard a high quality of clinical care for patients (Gmc, 2013).Nursing audit measures the quality of nursing care actually given to patients (Jairus \& Walia, 2011).

As regards to education, the highest percentage of women were illiterate similary, El-hassani et al., (2016) who studied the Fetal outcome in elective versus emergency cesarean deliveries at Souissi Maternity Hospital, Rabat, Morocco and found that there was statistically significant relationship between cesarean section and illiterate women $(\mathrm{P}=$ 0.049).On the opposite side other study done by Goodman et al., (2011) studied the factors related to satisfaction of childbirth in south -eastern United States who found that most of studied women were highly level of education. These differences can be explained by differences in cultures \& communities. According to the present study findings, the majority of the studied women were housewives and living in 
rural areas. In the same line, these findings were also in agreement with Mohamed et al., (2012) who studied perspectives of women related to the quality of nursing care provided after cesarean section in Maternity Hospital of Ain Shams, Cairo, Egypt who found that more than three quarters of women were housewives. In addition three quarters of the women were living in rural areas while the rest of them were from urban areas. This reflected women's needs for more health advices and extension of postpartum care services.

As regards to measuring vital signs every 15 minutes for one hour then every 30 minutes for one hour then every hour until discharge from recovery area. The findings of the present study revealed that nurses didn't measure vital signs in the same frequency and by asking nurses about their reasons of not doing the standardized nursing care they said that their decrease in number ( 2 nurses every shift) with increasing the number of cases is the principle cause, also lack of time and lack of resources like pulse oximetry in postpartum ward were the other causes to adhere to the standardized nursing care.

This result is in agreement with Moustafa et al., (2013) who studied the relationship between Assuit university hospital, Egypt and King Fahd Gizan hospital, Saudi Arabia as regards the ideal nursing care among post cesarean section women which observed not measuring vital signs in the same frequency in Gizan and Assuit hospital.

This study is in disagreement with Mohamed et al., (2012) who studied perspectives of women related to the quality of nursing care provided after delivery in Maternity Hospital of Ain Shams Cairo, Egypt. They found that nearly two thirds of women were observed their vital signs by nurse. After implementation of teaching strategy (booklet), there was a statistical significant improvement in all items of measuring vital signs like temperature, pulse, blood pressure and respiration which was done by internship student of faculty of nursing after my instructions and supervision of them except in measuring oxygen saturation by pulse oximetry as there was no pulse oximetry in postpartum ward. As regards to maternal comfort and assessment the findings of this study revealed that complete physical assessment is not done in all cases and assisting women in positioning and feeding is not done in the vast majority of cases and by asking nurses about their barriers they said that lack of their knowledge how to do complete physical assessment, lack of time, increasing number of cases and decreasing number of nurses every shift and they depend on the presence of relatives to assist the women in positioning and feeding.
These results were in disagreement with the study done by Elander et al., (2009) which reported that the responsibility of nurses that help to decrease pain include comfort measures such as changing the position of patient and straightening bed linen. After implementation of a teaching strategy there was no significant improvement in doing complete head to toe physical assessment as the barriers not corrected as they didn't had the knowledge and time to do it .but there was a significant improvement in helping woman in positioning and feeding her newborn.

As regards to palpating uterine funds every 15 minute for one hour then every 30 minutes for one hour then every hour until discharge from recovery area. The findings of this study revealed that only one fifth of women receive this care correctly as it is done every shift in doctor round only and by asking nurses about their barriers they said that it is doctor duty. These findings were in agreement with Mohamed et al., (2012) who studied perspectives of women related to the quality of nursing care in Maternity Hospital of Ain Shams -Cairo, Egypt who found that palpating uterus done only in about one fifth of cases. In the other hand it contradicts a study done by Ibrahim et al., (2010) who studied assessment of routine management of third stage of labour for normal delivery in women's health center and Eleman hospital for obstetrics and gynecology .who found that uterine massage was done for the vast majority of women, Chiechi et al., (2011) who studied the management of postpartum haemorrhage found that uterine massage in Ireland, Spain and Denmark was done in $100 \%, 98 \%, 96 \%$ respectively. This result is in agreement with David et al., (2011)who used audit to improve the quality of maternity care in countaries which is resource limitted (rural Tanzania)they found that doing of fundal massage immediately after delivery of the placenta followed by palpation is low in most setting.

These differences can be explained by differences of setting, polices and qualifications of working nurses. After implementation of a teaching strategy, there was highly significant improvement in palpating uterine fundus (p-value 0.000) as it is done by student and internship nurses under my supervision. As regards assessing the wound for signs of infection such as increasing pain, redness and discharge and assessing signs of bleeding and wound separation it is done correctly in more than one half of women, These findings were in agreement with Moustafa et al., (2013) who found that evaluating the dressing every shift is done accurately (100\%) in both hospitals Assuit University hospital and King Fahd hospital in Gizan. 
As regards encouraging women to wear loose comfortable clothes, the findings of this study revealed that the vast majority of women didn't receive these advices and by asking nurses about their barrier in this they said because of lack of their time for communication with women as they had work over load. This result was in agreement with Mohamed et al., (2012) who found that most of the mothers reported that they didn't receive sufficient postpartum advices.

After implementation of a teaching strategy there was significant improvement (p-value 0.002) as some nurses began to talk to women about the importance of wearing loose comfortable clothes.

As regards assessing IV site for appearances and patency initially and every two hours, The findings of this study revealed that it is done incorrectly in all cases as it is done only when women had IV solution or IV medication and by asking nurses about their barriers they said because of lack of their time and increasing number of cases with decreasing number of nurses. This result was in disagreement with Ingalls \& Salerno (2009) who reported that intravenous solutions must be carefully monitored to prevent giving it all slowly or rapidly.

After implementation of a teaching strategy there was significant improvement (p-value 0.000) in assessing IV site for appearance and patency.

As regarding encourging early mobilization when women's sensation returns to normal it is done correctly in the vast majority of cases in pre orientation and in all cases in post orientation .These findings were in agreement with Moustafa et al., (2013) who found that encouraging women for early ambulation was done accurately (100\%) in both hospitals King Fahd hospital in Gizan and Assuit University hospital. but other items of mobilization such as sitting the woman out of bed, the nurse present when the woman first ambulate and check the woman pressure areas when return to ward were not done to all of cases.

These findings can be explained by deficient number of nurses with increase number of cases and lack of time.

After implementation of a teaching strategy there was significant improvement in sitting the woman out of bed and in advising the woman to have nurse present when she decide to first ambulate and there were no significant improvement in checking the woman pressure areas when return to ward and by asking nurses about reasons of not doing that they said lack of their time and increase number of cases. As regards care of baby born by C.S, the findings of this study showed that it was correctly done in all cases.This result was in agreement with Nadew (2016) in his research "Clinical Audit on the attendance of pediatric medical team at deliveries in Metropolitan hospital in western Australia who found that the pediatric team was attended all instrumental deliveries and caesarean sections. This result reflected that women's Health University Hospital, Assuit followed RCOG recommendations about care of baby born by C.S.

As regards encouraging skin to skin contact between woman \& newborn the findings of the present study revealed that it was not done in all cases and Offering support to help woman start breast feeding, was not done in the vast majority of cases and by asking nurses about their barriers in this, they said skin to skin contact not in hospital policy in operating room and they had lack of time to help woman start breast feeding and they depend in this on the presence of her relatives.

After implementation of a teaching strategy there was no significant improvement in encouraging skin to skin contact between woman \& newborn because their barriers were not corrected but there was significant improvement in offering support to help woman start breast feeding.

These findings is in disagreement with a study done by Tapiwa \& Alepile, (2011) who assess the quality of care given during the postpartum period in Northern Botswana.They found that more than three quarter of study subjects kept newborn in skin to skin contact with the mother.

These differences can be explained by differences in polices between hospitals.

\section{Conclusion}

There was a big gap between the current and the ideal practices of care which provided to women undergoing cesarean section at Women's Health Hospital, Assiut University and the main barriers of not doing the ideal care were decrease number of nurses with increased number of cases, lack of nurses time, knowledge and lack of resources in postpartum ward after implementation of a teaching strategy some items of care were improved. The total number of all deliveries (normal vaginal deliveries \&cesarean sections) was 13115 in year 2016.the number of cesarean sections only was 6064(46.2\%) and normal deliveries were 7051(53.8\%).

\section{Recommendations}

Increasing the number of nursing staff in the postpartum ward to increase the quality of service.

Nurses in post natal unit should have continous training courses for the ideal postpartum care.

Government should recruit qualified staff to ensure quality of care is given to patients.

Further research studies are needed to identify the gaps in practices \& fulfilling it. 


\section{References}

1. American Congress of Obstetricians \& Gynecologists and Frequently Asked Questions, (2015): Cesarean Birth, Mailing Address: PO Box 70620, Washington, DC 200249998

2. Chiechi, Winter C., Macforlan (2011): study variations in policies for management of third stage of labor and immediate postpartum haemorrhage, BIOG an international journal,DOI:10.1111-147

3. Clinical Audit Support Centre (2015): What is clinical audit? Email: info@clinicalauditsupport.com http://www.clinicalauditsupport.com

4. David E., \& Hellstrom G., (2011): Community factors affecting rising caesarean section rates in developing countries: an analysis of six countries. Soc Sci Med 2008. Oct; 67(8):1236-1246 10.1016/j.socscimed.2008.06.03

5. Egypt Demographic \& Health Survey(2014): Main Findings, Ministry of Health and Population Cairo, Egypt ,El-Zanaty and Associates, The DHS Program, ICF International Rockville, Maryland, U.S.A

6. Elander G., Hellstrom G., \& Quarnstrom B., (2009): Pediatric Nursing, vol 1 - 19, No3

7. I-hassani A., Benzouina S., Boubkraoui M., Mrabet M., Chahid N., Kharbach A., \& Barkat A., (2016): Fetal outcome in emergency versus elective cesarean sections at Souissi Maternity Hospital, Rabat, Morocco: Pan Afr Med J. 2016; 23: 197 doi: 10.11604/pamj.2016.23.197.7401

8. Evans C., Mikim Y., \& Yari K., (2014): using direct clinical observation to assess the quality of cesarean delivery in Afghanistan ,an exploratory study, BioMed central BMC pregnancy and child birth 10-1186/1471-2393-14-176

9. Gibbons L., Belizán J., Lauer J., Betrán A., Merialdi M., \& Althabe F., (2010): The Global numbers and costs of additionally needed and unnecessary cesarean sections performed per year: Overuse as a barrier to universal coverage. World Health Report 2010. Background paper No 30, s. 1-32 WHO, Geneva, 2010.

10. Goodman P., Mackey M., \& Tavakoli A., (2011): Factors related to childbirth satisfaction, Journal of advanced nursing, April, Volume 46, Issue 2, pages 212-219

11. Gregory K., Jackson S., Korst L., \& Fridman M., (2012): Cesarean versus vaginal delivery: whose risks? Whose benefits, Am J Perinatol, 29(1):7-18. Doi: 10.1055/s-0031-1285829. Epub 2011 Aug 10.

12. Ibrahim M., Makhlouf M., Khamise A., (2010):Assessment of routine management of third stage of labour for normal delivery in women's health center and Eleman hospital for obstetrics and gynecology .Cairo university journal,june 2012,Vol80, No2,june :197-188

13. Ingalls J., \& Solorno C., (2009): Maternal and child health Nursing, 7 th Edn C.V. Mosby Co., P 335- 340

14. Jairus R., \& Walia I., (2011): Nursing Audit .The nursing Journal of India, June . 2011, volc11No 6

15. Kayiga H., Ajeani J., Kiondo P., \& Kaye D., (2016): Improving the quality of obstetric care for women with obstructed labour in the national referral hospital in Uganda: lessons learnt from criteria based audit 16-152

16. Mohamed H., Enggar N., \& Lamadah S., (2012): Women perspective regarding the quality of postpartum nursing care in Ain Shams Maternity Hospital-Cairo, Egypt Journal of American Science, 2012, 8 (2)

17. Moustafa M., Mohamed S., \& Tosson M., (2013): Ideal nursing care relationship between Assiut University Hospital and King Fahd Gizan Hospital among post cesarean section care, AAMJ, Vol. 11, N. 2, April, 2013

18. Nadew G., (2016): Clinical Audit on pediatric medical team attendance at deliveries in an outer Metropolitan hospital in western Australia International Journal of Medical Students 17(2): 143-147

19. Pirkle, C., Dumont. A., \& Zunzunegui (2011): Criterion based clinical audit to assess quality of obstetric care in low and middle income countries: a systematic review, International Journal for Quality in Health Care 2011; Volume 23, Number 4: pp. 456- 463

20. Tapiwa M., \& Alepile E., (2011):An evaluation of the quality of care midwives provide during postpartum period in northern Bostwana.thesis submitted for partial fulfillment of the requirement of master of philosophy degree in international community health.institute of general practice and community medicine.

21. Tristar Horizon Medical Centre (2010): quality-in-health-care, Newsroom https://www.acog.org/Patients/FAQs/CesareanBirth-C-Section. https://www.ncbi.nlm.nih.gov http://www. dhsprogram.com https://www.ncbi.nlm.nih.gov http://www.americanscience.org. http://www.tristarhorizon.com/about/newsroom/w hat-does-quality-in-health-care-mean 